\title{
Possible Mesoamerican Naked-Eye Observation of Sunspots - VII: Evidence from the Jade Mask of Río Azul and Related Artifacts
}

\author{
Richard R. Zito \\ Summerhaven Observatory, P.O. Box 663, Mt. Lemmon, AZ 85619, USA
}

Received January 25, 2021; Revised April 7, 2021; Accepted April 18, 2021

\section{Cite This Paper in the following Citation Styles}

(a): [1] Richard R. Zito , "Possible Mesoamerican Naked-Eye Observation of Sunspots - VII: Evidence from the Jade Mask of Río Azul and Related Artifacts," Sociology and Anthropology, Vol. 9, No. 2, pp. 7 - 18, 2021. DOI: 10.13189/sa.2021.090201.

(b): Richard R. Zito (2021). Possible Mesoamerican Naked-Eye Observation of Sunspots - VII: Evidence from the Jade Mask of Río Azul and Related Artifacts. Sociology and Anthropology, 9(2), 7 - 18. DOI: 10.13189/sa.2021.090201.

Copyright@2021 by authors, all rights reserved. Authors agree that this article remains permanently open access under the terms of the Creative Commons Attribution License 4.0 International License

\begin{abstract}
Many cultures of antiquity have made naked-eye observations of large sunspot displays. The Chinese, Japanese, Koreans, and Greeks, have all made such observations. These observations are still important because they give astronomers data about solar activity prior to telescopic observations beginning in 1610. A detailed examination of diverse objects from the Mayan Early Classic Period, described in reports I, III, IV, V, and VI of this series, suggests that the Maya were also monitoring naked-eye solar activity. This extra data set is of great importance because there are some discrepancies between Asian records (usually considered reliable) and what would be expected from ${ }^{14} \mathrm{C}$ measurements and other physical data. One of these discrepancies will be resolved in this report using Mayan data. Mayan Sun God iconography shows the appearance of a spotted Sun God during times of high solar activity and a spotless Sun God during periods of the quiet Sun. Up to this report, four criteria were used to select artifacts for the series of papers in this study: 1) the artistic motif must be present (Sun God with or without spots), 2) the artifact upon which the image occurs must be datable, 3) solar activity levels must be verifiable by direct observation from some other ancient culture, 4) observations must be substantiated by physical data (e.g. ${ }^{14} \mathrm{C}$ and ${ }^{18} \mathrm{O}$ data, tree ring analysis, nilometer data, etc.). And, of course, the artifacts chosen should span the Early Classic Period. It is natural to ask if other spotted deities track physical solar activity as well. In this report, the appearance of spots on the Venus God is examined.
\end{abstract}

Venus is a close companion of the Sun, both physically and by familial relationship within the Mayan pantheon. The datable Jade Funerary Mask of Río Azul is one such Venus God image. Other Venus God images are also examined. The appearance (ca. 400 AD), disappearance (668 AD), and reappearance (ca, $700 \mathrm{AD}$ ) of facial spots on solar deities as a function of time seems to track solar activity and is in agreement with physical data.

Keywords Maya, Jade Mask, Río Azul, Sunspots

\section{General Problem Statement}

Previous papers of this series have shown that the spotted Sun God, or Sun God stand-in like Hun Ahau (one of the hero Headband Twins who becomes the Sun) [1], appear during times of the active Sun, while iconographic spots are absent during times of the quiet Sun. The connection between the spotted Sun God in the Early Classic Period (reports I, III, IV, V, and VI [2,3,4,1,5]) and Late Post-Classic Period (report II [6]) with physically observable and implied solar activity seems a reasonable conjecture. However, it is natural to ask, "What about other spotted deities? Their spots can't all be identified with physical sunspots." In fact, this is quite true, as was demonstrated with the spotted Moon God in paper VI on 
Yaxchilan Lintel 48 [5]. There, the spots were possibly an artistic response to the fact that the Moon has a mottled appearance to the naked eye. And, the Moon is visible at night when the jaguar is active. Hence, jaguar spots cover the Moon God's entire body. Furthermore, the Moon God never loses his spots as a function of time. However, sometimes the spots on deities other than the Sun God seem to track solar activity and may come and go, possibly providing useful sunspot information. An example of this phenomena was the Maize God, Hun Hunahpu, (the father of the Sun God) in report III on the Hauberg Stela [3]. And, a recent discovery made in the Mayan pottery collection of the Tucson Museum of Art (TMA), Tucson, Arizona, also indicates a Sun-maize connection.
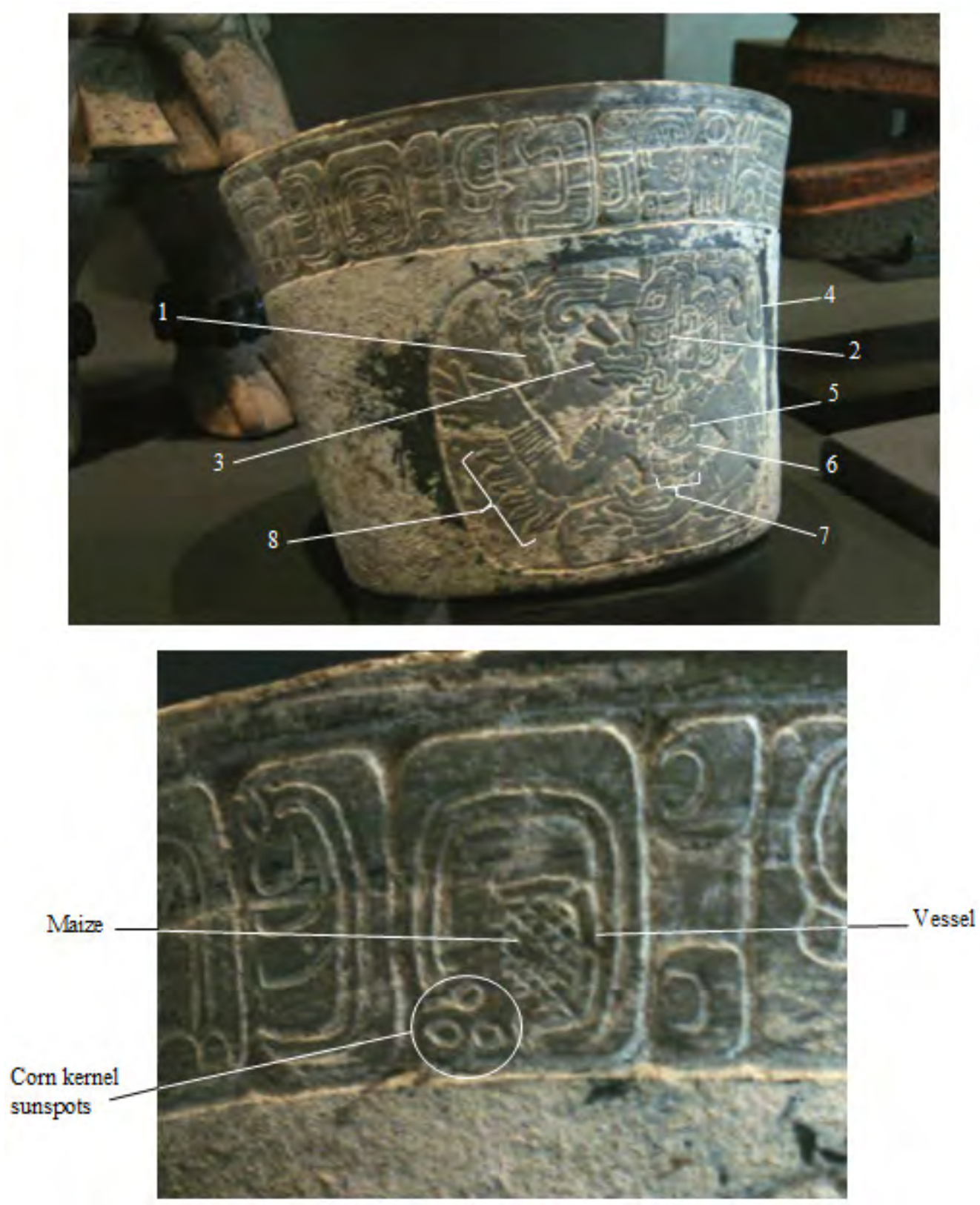

Figure 1. A) Vessel 1971.20 (Yucatán, 600-900 AD) in the Mayan pottery collection of the Tucson Museum of Art. The inscription around the rim typically states the contents of the vessel and its owner, while the deity on the main body of the vessel is Tlaloc (Chac, or God B) the Rain (and Lightning) God. He has 1) the "lightning serpent” in his right hand, 2) square "goggles" around his eye, 3) the long snout of the "flood caiman", 4) storm clouds emanating from his headdress, 5) a glyph on his chest (T778) associated with Thompson’s “long-nosed God”, 6) a cloud glyph beneath T778, 7) a “flour de le” motif (actually Plumeria rubra petals) beneath the cloud glyph, a Thompson affix (125) associated with an Ahau or "Lord”, and finally 8) feathers on his right arm that look like tongues of flame. These eight attributes constitute a signature equivalent for "Chac”. B) This key cartouche of the rim inscription should be read as "a vessel for maize”. Three spots forming an equilateral triangle are visible in the lower left, indicating an active Sun with sunspots large enough to be visible to the naked-eye. Photos by author 
The TMA vessel, identified as specimen number 1971.20, is shown in figure 1A and is believed to have a Yucatán provenance. Around the rim is a line of glyphs that typically contain two pieces of information; viz. what the vessel contained (probably maize), and who owned it (a name plus honorific title). One cartouche (figure 1B) is fairly simple, and shows a vessel containing maize. Pottery vessels are represented fairly literally, so that this glyph should be considered a variant of T686 [7]; which, incidentally, has a profile that looks very much like the vessel it is written on. The contents can be identified as maize because it shows the close-packed phyllotaxis of kernels on a corncob as seen in other examples of Mayan art (e.g. the corn kernel belt and necklace of the Corn God [8]). 1 Finally, the cartouche contains three small circles forming a small equilateral triangle, the signature of an active Sun displaying naked-eye sunspots. Perhaps these "spots" are also corn kernels pouring from the vessel depicted - a kind of written pun emphasizing the relationship between the Sun and the growth of maize. Finally, the main figure on the body of the vessel is Tlaloc (Chac, or God B) the Rain (and Lightning) God, often associated with maize [9]. So, here on this piece of pottery there is a very compact statement connecting the growth of maize to the three essentials for all plant life: warmth (from the Sun God), sunlight (from the Sun God), and water (from God B). Ancient atmospheric carbon-14 levels imply that sunspot activity should have peaked around $700 \mathrm{AD}$. The TMA has assigned a date of $600-900 \mathrm{AD}$ for this piece. So the sunspot triplet may, in fact, be related to the physical sunspot activity to be described. It is unfortunate that a better date is not available for this specimen. Work on 1971.20 is still preliminary, but ongoing.

In this report, two examples are considered in which the Venus God (GI), the brother of the Sun God (GIII), has facial spots that seem to be related to sunspot events. The Jade Funerary Mask of Río Azul is dateable and can be connected to the impressive naked eye sunspot sequence that began in $369 \mathrm{AD}$ and terminated in $400 \mathrm{AD}$. Furthermore, Copán Stela 1 is accurately datable, and shows an unspotted Venus God that is appropriate for the quite Sun period within which it was created.

\section{The Jade Funerary Mask of Río Azul}

The Venus God (GI) is the eldest brother of the Sun God

1 In addition to representations of corn, there are only a few other places where phyllotaxis (the shifting of identical figures in a row from one row to the next) commonly occurs in Mayan art and hieroglyphics. The first is in the depiction of a turtle carapace (top of a turtle shell, T625 and T626). In that case each "cell" is large, has jagged boundaries, and a small circle at its center [7]. The second is in the "checkerboard" pattern of the "shield" glyph (T594 and T624). On a smaller scale, "cross-hatching" may be employed to create the illusion of "shade" as in the half cross-hatched Kin (Sun) sign (T545), and Lord (Ahau; T540, T541). Nevertheless, a phyllotaxis of $1 / 2$ (shifting of one row of images by $1 / 2$ of a "cell" with respect to the previous row of images) is common in the patterns of Mayan textiles.
(GIII) in the Palenque Triad. The Sun's younger brother (GII) has been associated with Mars or Jupiter [8], but a more likely association is Mercury [10,11,12]. Therefore, as a related deity that precedes or succeeds the Sun at sunrise or sunset respectively, it is not surprising to find instances where GI is spotted when GIII is spotted. The Jade Funerary Mask of Río Azul is one example of this phenomenon. The mask, featured on the cover of National Geographic Magazine [13] (Figure 2) and currently believed to be in the Barbier-Mueller collection in Switzerland according to a web site that tracks contraband [14], was removed from context so that a great deal of information about it was lost. Nevertheless, inspection of the artifact revealed that: 1 ) the mask appears to be made of some kind of "jade", however its true chemical composition is unknown;2 2) an inscription on the back of the mask indicates that it belonged to king Zak Balam of Río Azul who, according to Stela 1 of that city-state, ascended the throne in 392 or $393 \mathrm{AD}$ [15]; 3) the Venus God is depicted on the front of the mask, as characterized by his "downward pointed tongue" (called a "shark tooth" by most iconographers), and spiral pupils; 4) a single inscribed circle exists on each cheek of the mask (GI usually has 0,1 , or 3 "sunspots" on each cheek and many examples of each are known [8,16]); and 5) a Kin (Sun) sign on his head to indicate close association with the Sun (many examples of this are also known with the Kin sign usually placed above the head or on the forehead).

2 The word "jade" is a general term that refers to several different minerals (jadite, nephrite, and fuchsite among others) that have a similar appearance, but different chemical composition. Jadite is a silicate of sodium and aluminum, $\mathrm{NaAl}(\mathrm{SiO} 3) 2$, and is found in both Asia and Mexico [29]. Whereas the actinolite variety of nephrite, $\mathrm{Ca} 2(\mathrm{Mg}, \mathrm{Fe}) 5(\mathrm{OH}) 2(\mathrm{Si} 4 \mathrm{O} 11) 2$, is a silicate of calcium, magnesium, and iron that substitutes for some of the magnesium, and is found in the Motagua Valley, Guatemala. However, Burma is another important source of nephrite [30]. Adams [15] believes the mask to be made of fuchsite (a "sub-jade"), whose chemical composition is $\mathrm{K}(\mathrm{Al}, \mathrm{Cr}) 2 \mathrm{AlSi} 3 \mathrm{O} 10(\mathrm{OH}, \mathrm{F}) 2$. This rare mineral comes from Guatemala, but it is also found elsewhere [30]. All of these minerals are made up of elements that are common and widely distributed in the Earth's crust. Only a trace element analysis can unambiguously prove that the raw materials of the mask came from a Central American locality. Although the grammatically correct inscription on the mask would be almost impossible to fake, authentication and provenance are always issues when an artifact suddenly appears on the market without proper documentation of the context of the find. The Jade Funerary Mask was simply offered for sale, sometime between 1979 and 1986, by a collector for a suggested price of nearly half a million U.S. dollars. In 1986 the National Geographic Society, in collaboration with the Guatemalan Institute of Anthropology and History, offered \$10,000 (U.S.) for a photograph that shows the mask in its undisturbed context. As of Aug. 14, 2012, no photograph of the mask in context has ever been produced [14]. Should this important artifact ever appear on the market again, non-destructive testing via Auger Electron Spectroscopy (AES) could resolve any uncertainties. AES can easily distinguish the light elements $\mathrm{Na}$ and $\mathrm{Al}$ from the heavier $\mathrm{Ca}, \mathrm{Mg}, \mathrm{Cr}$ and $\mathrm{Fe}$, and can detect trace elements as well. All that is necessary is to wipe the part of the mask's surface to be examined with distilled water to remove any surface salt $(\mathrm{NaCl})$ from fingerprints, groundwater, and soil. The mask can be examined as a whole, provided the spectrograph has a large enough vacuum chamber and a strong enough pump to outgas the mask. A more practical approach would be to remove and analyze a minute piece of jade; a billionth of a gram (10-9 g) is more than enough material for the AES electron beam. For now, all that is available for study is the artist's reconstruction on the cover of National Geographic Magazine [13]. 


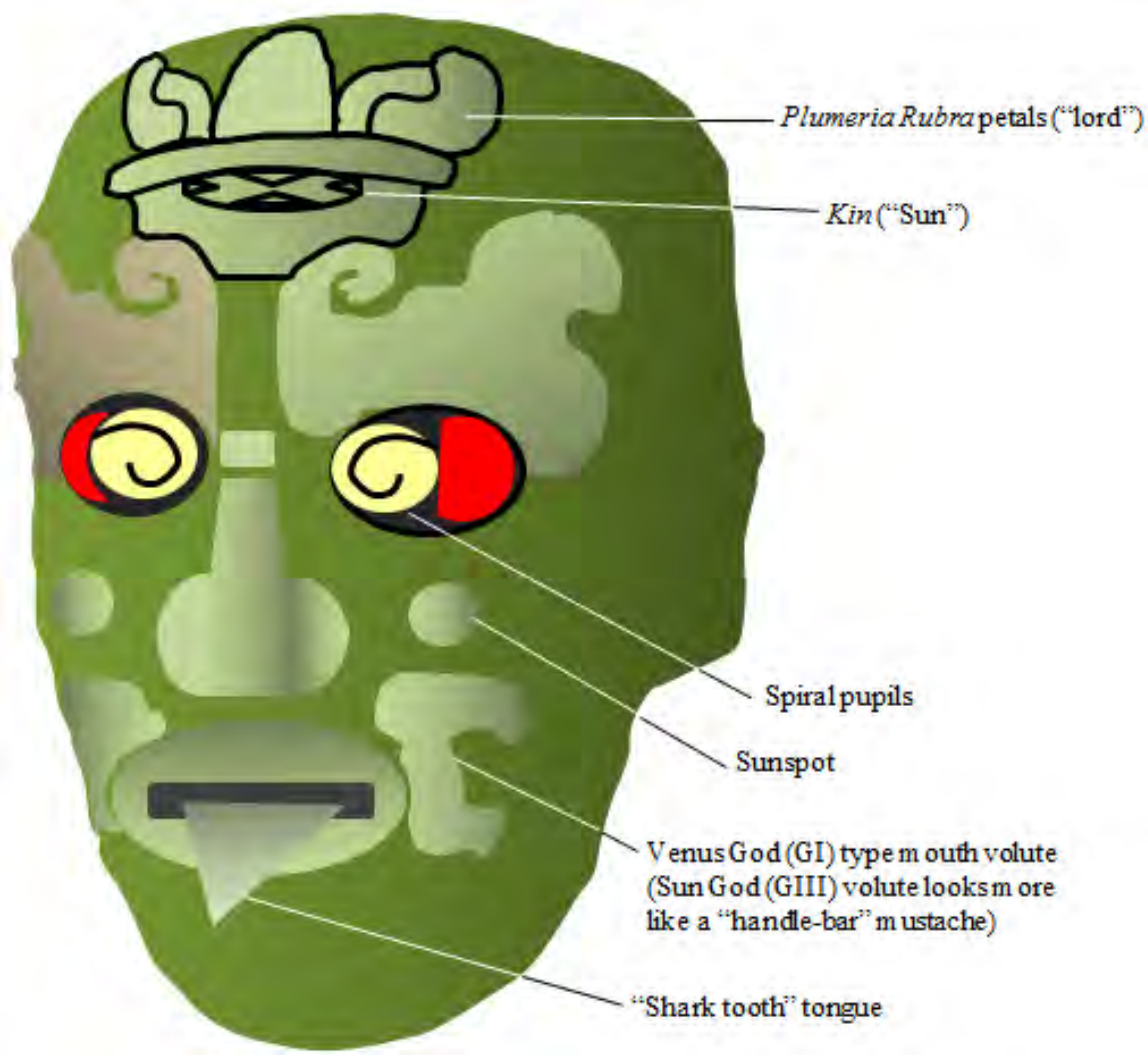

Figure 2. Author's computer rendition of the Jade Mask of Río Azul. The tattoo or tiara on his forehead should probably be read as "Sun Lord". However, he is definitely the Venus God (GI). He has: 1) spiral pupils, 2) Venus-type mouth volutes, and 3) a "shark-tooth" tongue. These are all signature equivalents for Venus (GI). Most importantly for this publication, the mask has two sunspots, one on each cheek.

Item 5 also requires some elaboration. Clearly the God head represented by this mask is not the Sun God GIII, but the brother of the Sun (Venus). The same mislabeling occurs on other GI artifacts as well as the Jade Funerary Mask $[8,16]$. Why was this done? First of all, Venus is never far from the Sun, and is often so close that it is caught in its glare. In fact, Venus will occasionally cross the solar disk. At times like these, there is a union between the Sun God and Venus. There is ample evidence that Mayan priest-astronomers observed the Venus transits of November 30, 1153 and/or June 1, 1275. This was demonstrated by Trejo and Allen in 2005 [17]. The Fresco Hall, at the southern end of the Central Plaza of the Post-Classic Mayapan ruins, shows descending personages (Venus God or a related deity) inside Sun circles of various panels. Physiologically, an obstacle (e.g. Venus or a sunspot) must cover at least $0.05 \%$ of the solar disk to be observable with the unaided eye [18]. Figure 3A shows that Venus can be viewed as a dark spot that covers $0.09 \%$ of the solar disk during transit. Venus is close to the limit of what can be observed on the face of the Sun with the unaided eye, but then again, the Maya knew exactly when and where to look since they were careful observers of the motions of Venus [8]. Furthermore, during solar conjunctions (or near conjunctions), deities other than the Sun God can receive a Sun God label (Kin sign marking), usually in the form of a tattoo on the God head. This was seen in report $\mathrm{V}$, where a peccary was labelled with a kin sign in reference to the solar eclipse of April 27, $450 \mathrm{AD}$ in which the Sun and the constellation of the peccary were closely spaced in the sky [1]. Therefore, the apparent "mislabeling" of the mask is not as unreasonable as one might at first think.

According to Stela 1 of Río Azul, Zak Balam ascended the throne in 392/393 AD. It is uncertain how long he lived, and ruled during a time of short life spans (shortened still further by executions of rulers resulting from city-state warfare). Nor is it known who his successor was. He may have been replaced by "Six Sky", but that is not certain [13, 15]. However, it is certain that by $440 \mathrm{AD}$ Governor $\mathrm{X}$ of the Tikal dynasty was in control [15]. Naturally, the Jade Mask, being a funerary device, must have been created at the end of Zak Balam's life, which may not have been long after 393. As will be discussed in detail in the section on Asian vs. Mesoamerican Sunspot Observations below, the dates 393-400 AD lie within an epoch of exceptional solar activity. Therefore, an active Sun exhibiting naked eye sunspots started from the king's accession and persisted through some, if not all, of Zak Balam's reign. Furthermore, Figure 3B shows that large sunspots can be as easy to observe as a Venus transit, sometimes much more so, although their occurrence is more unpredictable. Consequently, it is not unreasonable to suspect a physical sunspot motivation for the mask's iconography. 

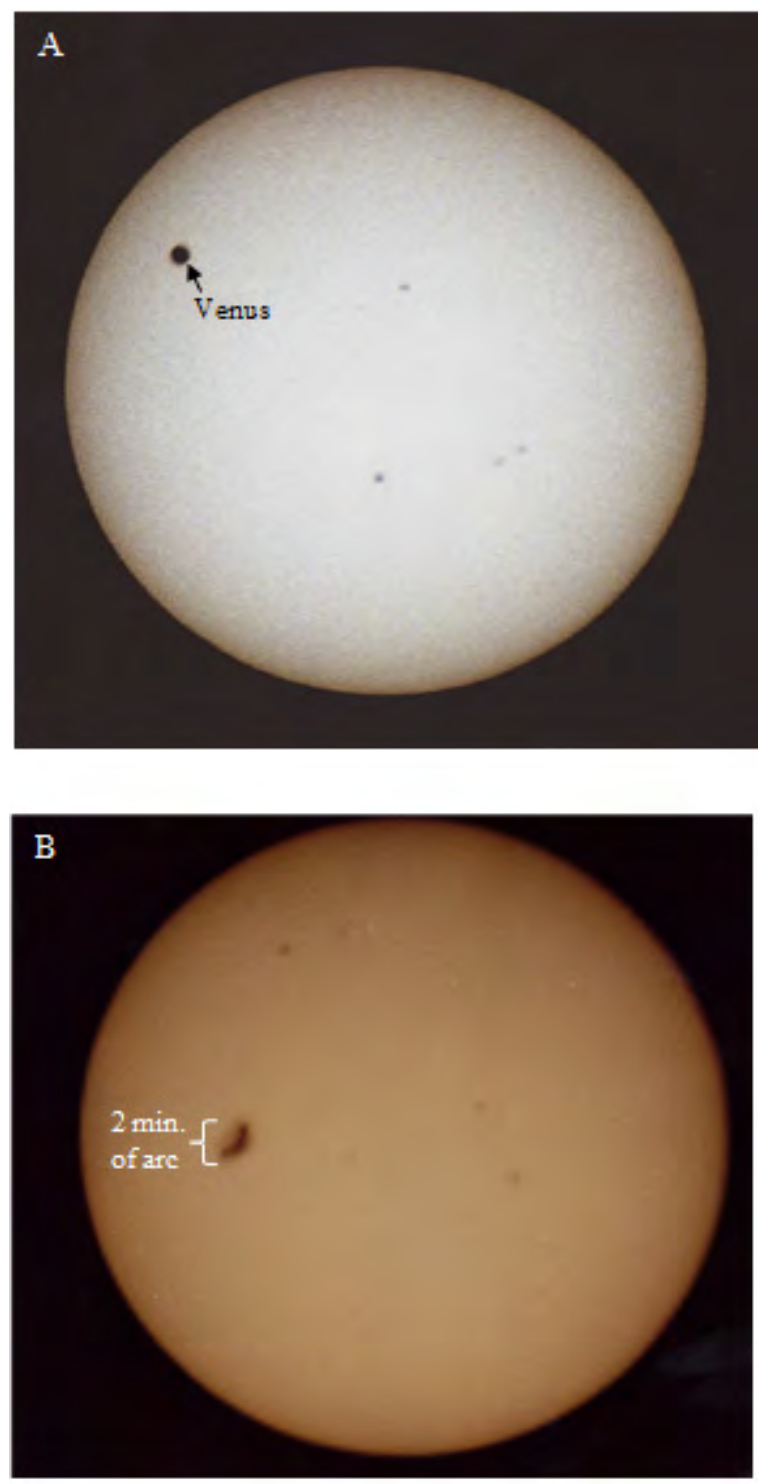

Figure 3. A) The transit of Venus on June 5, 2012. The transit is a naked-eye event (always use a solar filter for safety). However, good vision and good seeing are required. Under such conditions, Venus in transit will appear to be a small black speck on the Sun's face. The small sunspots in this photo would not be visible to the naked-eye. An observer with 20/15 vison in each eye can just barely sense Venus as an object of some extent on a clear evening at closest approach to Earth. B) A large naked-eye sunspot group visible on June 9, 1991. Coverage was $0.3 \%$ of the solar disk, 6 times the minimum required for naked-eye observation. Again, the small sunspots would not be visible to the naked-eye. Both photographs taken by the author at the focal plane of an f/11 C90 Celestron telescope (equivalent to a $1000 \mathrm{~mm}$ telephoto lens) on Kodak Ektar film (ASA 125) with exposures between 1/60 and 1/125 sec. For both photographs the lateral magnification was 18X, and a full aperture DECO solar filter was used

\section{Venus God at Copán}

"Negative data" are usually considered uninteresting in scientific investigations. However, in this case, the disappearance of facial spots from the Venus God says a great deal about the tracking of solar activity. After 400 $\mathrm{AD}$ sunspot activity seems to have disappeared for a century. And, according to Asian observations, another quiet Sun period occurred during the $7^{\text {th }}$ and $8^{\text {th }}$ centuries [19], and is concomitant with the disappearance of the spotted Venus God in the $7^{\text {th }}$ century. For example, a deceased royal ancestor from Copán has been represented as GI on Copán Stela 1 [8]. No spots can be seen on the cheeks of the royal face mask (styled as GI with spiral pupils) or the God head above it labeled with a Kin sign. The stela is dated May 3, $668 \mathrm{AD}$ (Gregorian equivalent) $[20,21]$. Copán Stella 1 will be discussed in more detail in a separate publication of the series on spotted solar deities in Late Classic Period iconography.

\section{Venus God of the Palenque Triad}

In the temple of the Foliated Cross, a text passage names three astronomical Gods, denoted by Heinrich Berlin as GI, GII, and GIII, because they always occur in that order [8, 22]. GI (in profile showing his "shark tooth" and a spiral pupil) is associated with the east, the ocean, and Venus 
which rises out of the eastern ocean before GII (usually, because of Venus' greater orbital radius) or GIII. GI seems to have three small spots under his eye. But, they are not in the usual arrangement of an equilateral triangle, and they are not in the usual facial location. Therefore, it is difficult to know if they are meaningful. God GII (Mercury) usually rises next. He doesn't seem to have much of a face, only a swirl of lines (usually representing clouds) around his head. Anyone who has made naked-eye observations of Mercury knows how easy it is to lose the planet in haze, mist, and clouds on the horizon. GII is associated with lightning, water, and agricultural growth. His title is "Young Lord of the Five Heavenly Houses" and he is always depicted as an infant, probably an oblique reference to the fact that he is usually the last "born" (seen) of the five naked-eye planets before the Sun rises. However, God GIII (with a signature Kin, or Sun, sign over his head) clearly shows a single (active Sun) cheek spot. The Temple of the Foliated Cross was dedicated in $692 \mathrm{AD}$ [22]. The suggestion is that the Sun was active at the very end of the $7^{\text {th }}$ century. This interpretation is further confirmed by the appearance of a spotted solar deity (thought by M.D. Coe to be Hunahpu, who becomes the Sun [23]) in Naj Tunich Cave. An adjacent text is dated $737 \mathrm{AD}$ [24]. As will be discussed below, the dates 692 to $737 \mathrm{AD}$ neatly bracket a broad peak in solar activity, as predicted by C-14 measurements, that was not reflected in Asian records. Both the Palenque Triad and Naj Tunich Cave will be discussed in more detail in a separate publication on Late Classic artifacts with spotted solar deities.

\section{Asian vs. Mesoamerican Observations}

During the time period from 369 to $400 \mathrm{AD}$, there were 10 naked eye sunspot observations from Asia in rapid succession [19]. These occurred on Nov. $27^{\text {th }} 369$, Mar. $29^{\text {th }} 370$, Jan. $28^{\text {th }} 373$, Dec. $26^{\text {th }} 373$, Apr. $6^{\text {th }} 374$, Jan. $10^{\text {th }}$ 375 , Apr. $2^{\text {nd }} 388$, July $17^{\text {th }} 389$, Dec. $13^{\text {th }} 395$, and Dec. $6^{\text {th }}$ $400 \mathrm{AD}$. These observations are recorded in the Chin-shu, chih. 3 The creation date of Balam's mask must fall within, or shortly after, this period of high solar activity.

There were no sunspot observations from Asia between Apr. 3, 579 AD and May 7, 826 AD [19]. This 247 year period has been thought to be an authentic period of the quiet Sun by Clark and Stephenson [19] because "during almost the whole of Chinese history since Han times [i.e. beginning in $206 \mathrm{BC}$ ], the acknowledged systematic and careful approach to observational astronomy and its

3 At this point a comment needs to be made concerning transliteration of Chinese to English. The reference "Chin-shu, chih" (Taiwanese) should be pronounced "Jin-shu, chih". The Jin Dynasty lasted from 266 - 420 AD. The Chinese sunspot observations come from this time period. "Shu" means "Book", as in a history book. And, "chih" means "treatise". So, "Chin-shu, chih" should be translated into English as "History of the Jin Dynasty: A Treatise”. compendious documentation, the abundance of records of various other day-time phenomena, and the deeply held belief that celestial phenomena were precursors of terrestrial events make it unlikely that only sunspots were omitted from the regular patrol.” Nevertheless, Clark and Stephenson do admit that the absence of naked-eye sunspots for almost two and a half centuries is "surprising." For the $7^{\text {th }}$ century, Mayan observations are in agreement as evidenced by the lack of facial spots on Copán Stela 1. However, the spotted Sun God (and possibly the Venus God) of the Palenque Triad (692 AD) as well as the solar deity of Naj Tunich Cave (737 AD) imply that solar activity at the beginning of the $8^{\text {th }}$ century may have been present. This conclusion agrees with the atmospheric C-14 data presented in the next section. The trends in Mayan art seem to track solar activity well, but it is still important to understand the lack of Asian observations.

Observations may have ceased because an observer died and left no students behind to carry on his work, or political/economic events may have disrupted his studies, or perhaps certain types of observations simply fell out of fashion. Or, perhaps the long $7^{\text {th }}$ century quiet Sun period eventually discouraged further observations until 826. It is difficult to conjecture what may have happened.

\section{Carbon-14 Measurements}

Atmospheric radiocarbon analysis [4] supports the notion of an active Sun for Zak Balam's jade funerary mask. Exactly when he died is uncertain, but it must have been after his accession (393 AD) and before Governor X took control (440 AD). During that time the atmospheric C-14 level decreased precipitously from its previous peak and bottomed out about 409 AD. The increase in the magnetic shielding of the Earth induced by sunspots would have been significant to cause such a drop. High shielding means low penetration of charged particles from cosmic rays into the upper atmosphere, where C-14 is produced by nuclear reactions.

After 411 magnetic shielding began to decrease and atmospheric radiocarbon production peaked around 450 $\mathrm{AD}$ (the center of the $5^{\text {th }}$ century quiet Sun period). After 450 shielding increased again [4], and the radiocarbon level fell and bottomed out by about 550, with many sunspots observed between 499 and 513 AD [19]. Then activity began to slow. Two modest quiet Sun C-14 peaks follow centered on 550 and $650 \mathrm{AD}$ [4]. The latter is probably responsible for the lack of spots on Copán Stela I (667 AD). Finally, the broad local minimum in atmospheric radiocarbon that bottoms out in 709 AD [4] suggests increased cosmic ray shielding due to an active Sun; consistent with physical sunspots and the art at Palenque and Naj Tunich. So, the previously described absence of Asian observations proximal to $709 \mathrm{AD}$ is puzzling. 


\section{Oxygen-18 Measurements}

Oxygen-18 is primarily a climate indicator. As such, the isotope's ability to track solar activity is indirect and limited. Generally, a quiet Sun correlates with a cold climate in the northern hemisphere. But, changes in ocean and air currents, cloud cover, the rate at which arctic ice melts, human activity (like deforestation), and many other complex factors, can affect O-18 levels in a way that may be at variance with what would be expected from observed solar activity and the C-14 measurements discussed in the previous section.

When the spurious factors above are held constant, O-18 tracks climate as follows. Water evaporating from tropical seas contains a more or less standard amount of the heavy isotope of oxygen (oxygen-18). As air circulates from the equator to the poles, heavy water molecules made of O-18 $\left(\mathrm{H}_{2}{ }^{18} \mathrm{O}\right)$ will freeze out first. In the northern hemisphere, by the time snow falls in Greenland, it is already depleted in $\mathrm{O}-18$ relative to O-16. When the Earth's climate is cold, the $\mathrm{O}-18$ depletion (called the O-18 anomaly, denoted by $\delta^{18} \mathrm{O}$, and measured in parts per thousand, \%, relative to SMOW or Standard Mean Ocean Water [25]) will be greater. That is to say, $\delta^{18} \mathrm{O}$ will be more negative. The reverse is true when the Earth's climate is warm. As snow builds up, year after year, snow is crushed into ice by its own weight. Therefore, examination of the O-18 content of ice cores in Greenland and Antarctica can be used to determine climate trends in the northern and southern hemispheres respectively.

In the first millennium of our era, the quiet Sun from 400 $\mathrm{AD}$ to $499 \mathrm{AD}$ was accompanied by a low in $\delta^{18} \mathrm{O}$ from $-29.1 \%$ to $-29.0 \%$ respectively, with an absolute minimum of $-29.2 \%$ in the year $450 \mathrm{AD}$; right in the center of the quiet Sun period, as might be expected. In the other extreme, $\delta^{18} \mathrm{O}$ rose to $-28.0 \%$ in the year $1000 \mathrm{AD}$ during the "Medieval Warm", and concomitant with the sunspot display of $974 \mathrm{AD}$. Between these two extremes, there was a conspicuous local $\delta^{18} \mathrm{O}$ maximum in the year $625 \mathrm{AD}$, when $\delta^{18} \mathrm{O}$ rose to just above the $-28.2 \%$ level. If there really were no naked-eye sunspots between the years 529 and 826, then why was the northern hemisphere so warm? The mean $\delta^{18} \mathrm{O}$ was about $-28.5 \%$ during this period, and it never fell below about $-28.8 \%$. The value of $\delta^{18} \mathrm{O}$ should have plummeted to $450 \mathrm{AD}$ levels, or less, as it did during the Maunder Sunspot Minimum (1645-1710 AD) when $\delta^{18} \mathrm{O}$ bottomed out at about $-30.0 \%$ [26]. This suggests that there may have been at least some sunspots during this period, in agreement with the predictions of atmospheric C-14 levels and Mayan artwork circa 700AD.

\section{Tree Ring Data}

As discussed in a previous publication [4], tree ring data support an active Sun for the estimated creation date of the Río Azul mask (ca. 400 AD). Therefore, that data will not be repeated here except by citation. What is new, and of great interest, is the tree ring data summarized in Figure 4 for the 100 years between 650 and $750 \mathrm{AD}$ [27]. The data are for Pinus longaeva (Rocky Mountain Bristle Cone Pine) at Methuselah Walk in California, USA. These are the oldest trees in the world, and their ring record stretches back 8000 years. Except for a single-year devastation in $699 \mathrm{AD}$ (probably fire) the tree ring record around the year 700 AD seems fairly smooth. Narrow rings correspond to a warm dry climate, while wide rings correspond to cool damp weather. In the graph of Figure 4A, the tree ring spacing is averaged over 10 years per data point. This procedure mitigates the effect of singular events (e.g. forest fires). The data set shows moist conditions in the Southwestern United States for the second half of the $7^{\text {th }}$ century. This condition is usually linked to quiet Sun periods in the American southwest. After about $700 \mathrm{AD}$, an active Sun drought seems to set in. This is in general agreement with the appearance of the Venus God at Copan, Palenque, and Naj Tunich. The physical condition of the Sun is usually not exactly coincident with tree ring events as seen in the close-up for the years 736 to $745 \mathrm{AD}$ in Figure 4, but may differ by several years. 

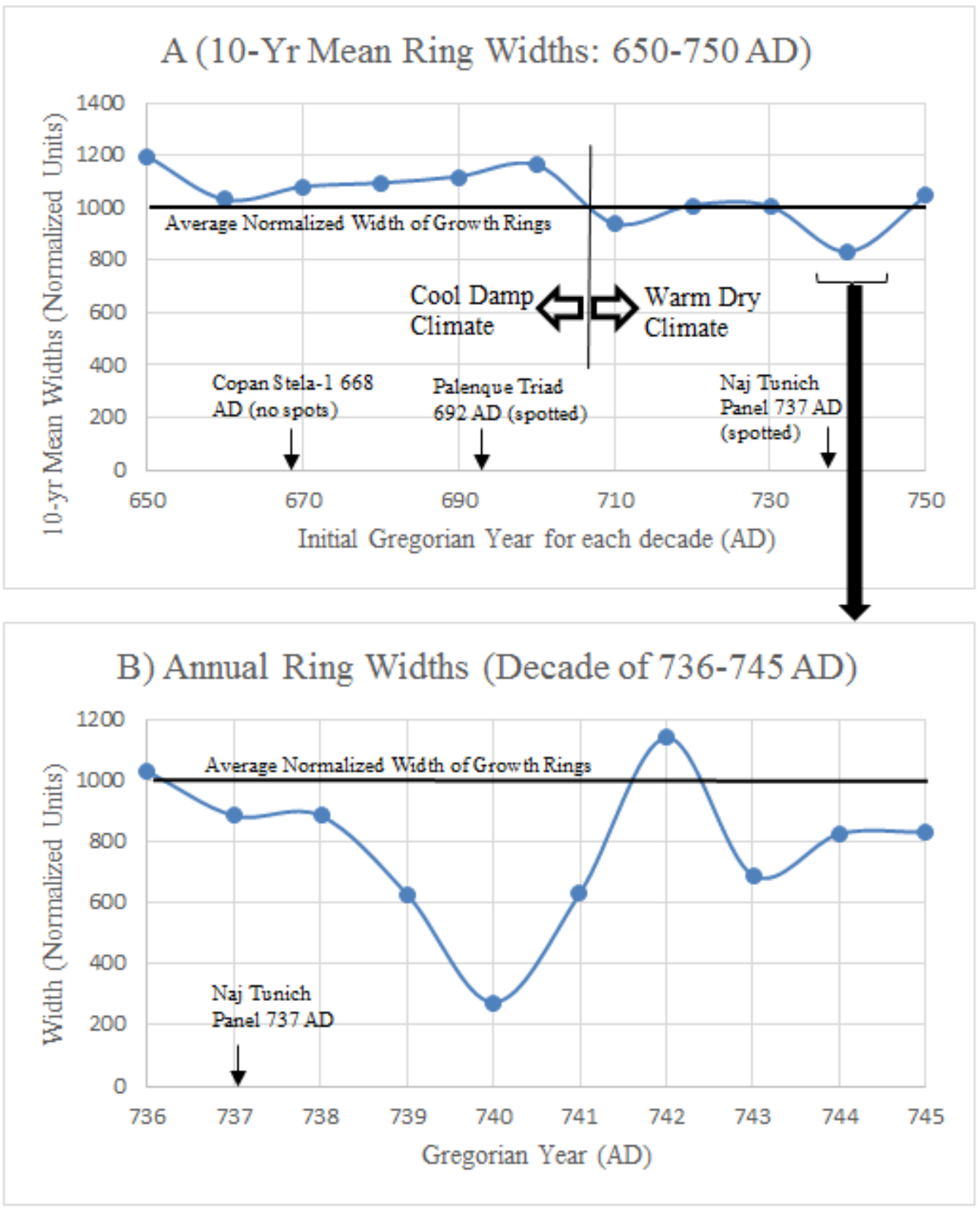

Figure 4. Tree ring data for the growth of Pinus Longaeva (PILO; Rocky Mountain Bristle Cone Pine). Tree ring widths are from the International Tree Ring Data Bank [27]. Widths are in "normalized units" such that 1000 represents average growth. A width less than 1000 indicates drought conditions, and above 1000 indicates wet conditions. Climate normally accounts for $63 \%$ of the growth variance [31]. A) Each data point is an average of 10 years of annual data, starting with the first year of the decade. B) Each annual data point is an average of 29 to 30 samples. All samples were collected by D.A. Graybill

\section{Nilometer Records}

Further evidence for the condition of the Sun circa 700 $\mathrm{AD}$ can be gleaned from Nile water level measurements [28]. Such records go all the way back to pharaonic times because of the importance of the annual floods to food production along the Nile. But, it is the Islamic records, starting in $622 \mathrm{AD}(1 \mathrm{AH})$, of the Medieval Period that are most relevant to this research. Especially the records from the "nilometer" on Rodah Island, Cairo. As in the southwestern U.S., solar activity (sunspot count) is linked to climate in the catchment area of the Nile tributaries through the El Niño phenomenon (the Southern Oscillation- ENSO). High water levels, and large differences between the high and low water levels, are associated with high sunspot counts, while the reverse is associated with a quiet Sun [28]. Figure 5 shows the amplitude of the 7.2-year Fourier component of the corrected nilometer data as a function of time. The 7.2-year component is part of a band of Fourier components from 7-10 years that is closely linked to the sunspot cycle. The data seem robust with little noise. Note the correlation 
between high water levels, and water level differences, and the climate and sunspot count. A small amplitude means that there is no connection between the observed water levels and the condition of the Sun. This, of course, happens when there are no sunspots (quiet Sun) over an extended period of time (many 11-year sunspot cycles). The large amplitudes circa 700 AD militate in favor of an active Sun, in agreement with Mayan artwork.

A
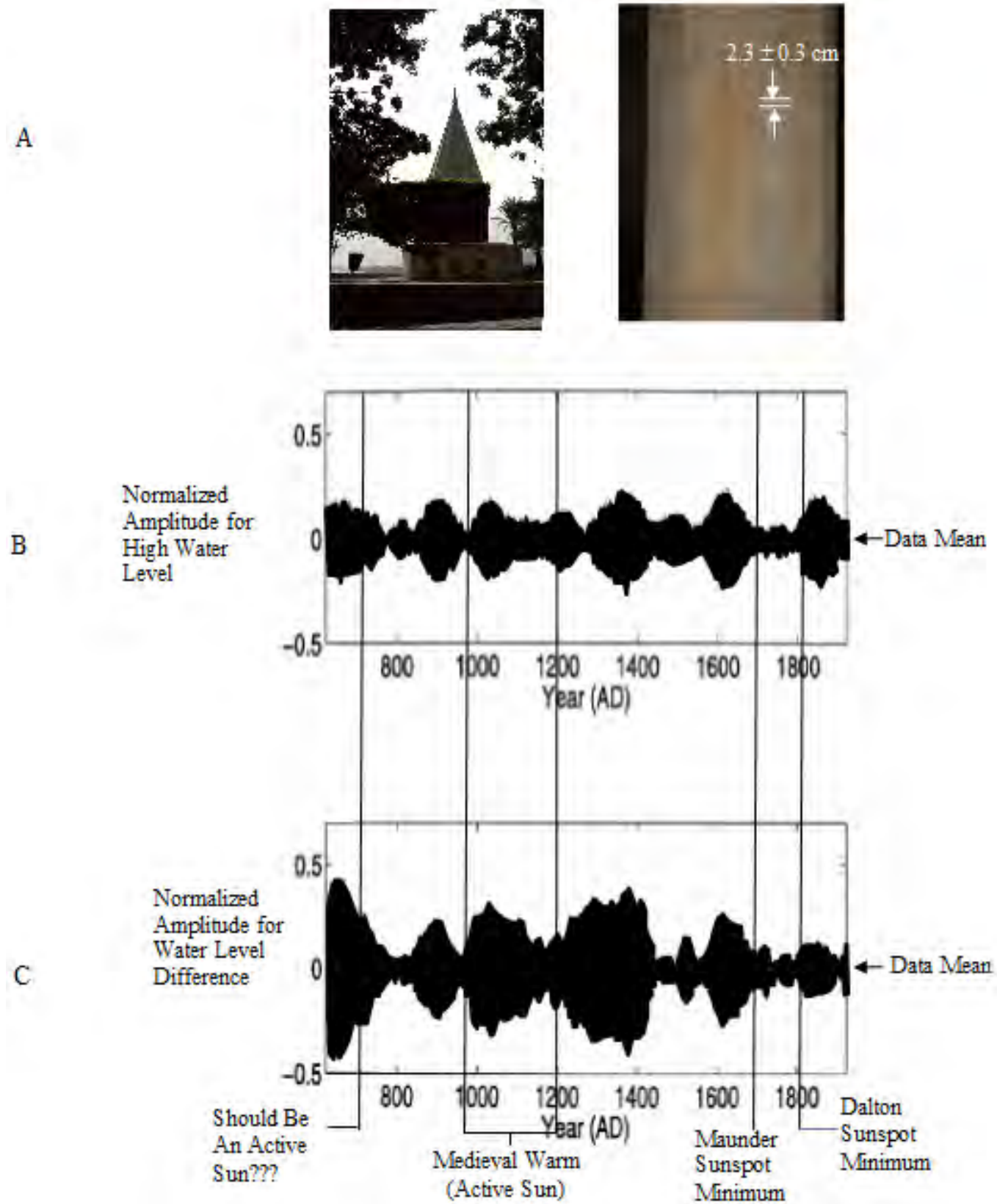

Figure 5. A) El Miqyas ("The Measurer”), the nilometer on Rodah Island, Cairo. On the left is the exterior elevation of the building. On the right is the interior "dipstick". Markings are in groups of five, with a separation of $2.3 \pm 0.3 \mathrm{~cm}$ between markings. Photos by author. B) Amplitude of the 7.2 year Fourier component of the corrected nilometer high water mark as a function of time [28]. C) Amplitude of the 7.2 year Fourier component of the difference between the corrected nilometer high and low water marks as a function of time [28]. Each data point employed a 100-year sampling window. Correction to the raw data included the use of a gap filling algorithm, detrending the time series, compensating for changes to the definition of a unit length (the cubit) with time, compensating for the rise of the Nile bed due to siltation, and compensating for the differences between lunar and solar calendars. Finally, the data was normalized about the mean by one standard deviation of the detrended time series 


\section{Conclusions}

There are several final comments to be made with regard to the spotted Venus God. First, it has been necessary to introduce material that will be discussed in more detail in subsequent publications on the Late Classic Period. This was necessary in order to show how this spotted deity tracks the physical condition of the Sun. The overlapping material will also help tie together the data from the Early Classic and Late Classic Periods, and make the transition between the two smoother.

Another important point is the apparent disconnect between the broad carbon-14 valley that seems to bottom out in $709 \mathrm{AD}$ [4], indicating an active Sun, and the absence of naked-eye sunspots in the Asian records from 579 - 826 AD [19]. The paradox is resolved when one observes that spotted solar deities occur on the Temple of the Foliated Cross (692 AD) in Palenque and on a panel in Naj Tunich Cave that dates to Oct. 31, 737 AD. These images imply naked-eye solar activity in the early $8^{\text {th }}$ century, and an omission in the Asian records. Furthermore, this supposition is supported in a general way by $\mathrm{O}-18$, tree ring measurements, and data from nilometers in the Cairo area. Still more data from the Maya will be presented in the next publication in this series. The absence of sunspots in the Asian solar record has troubled astronomers for over 40 years!

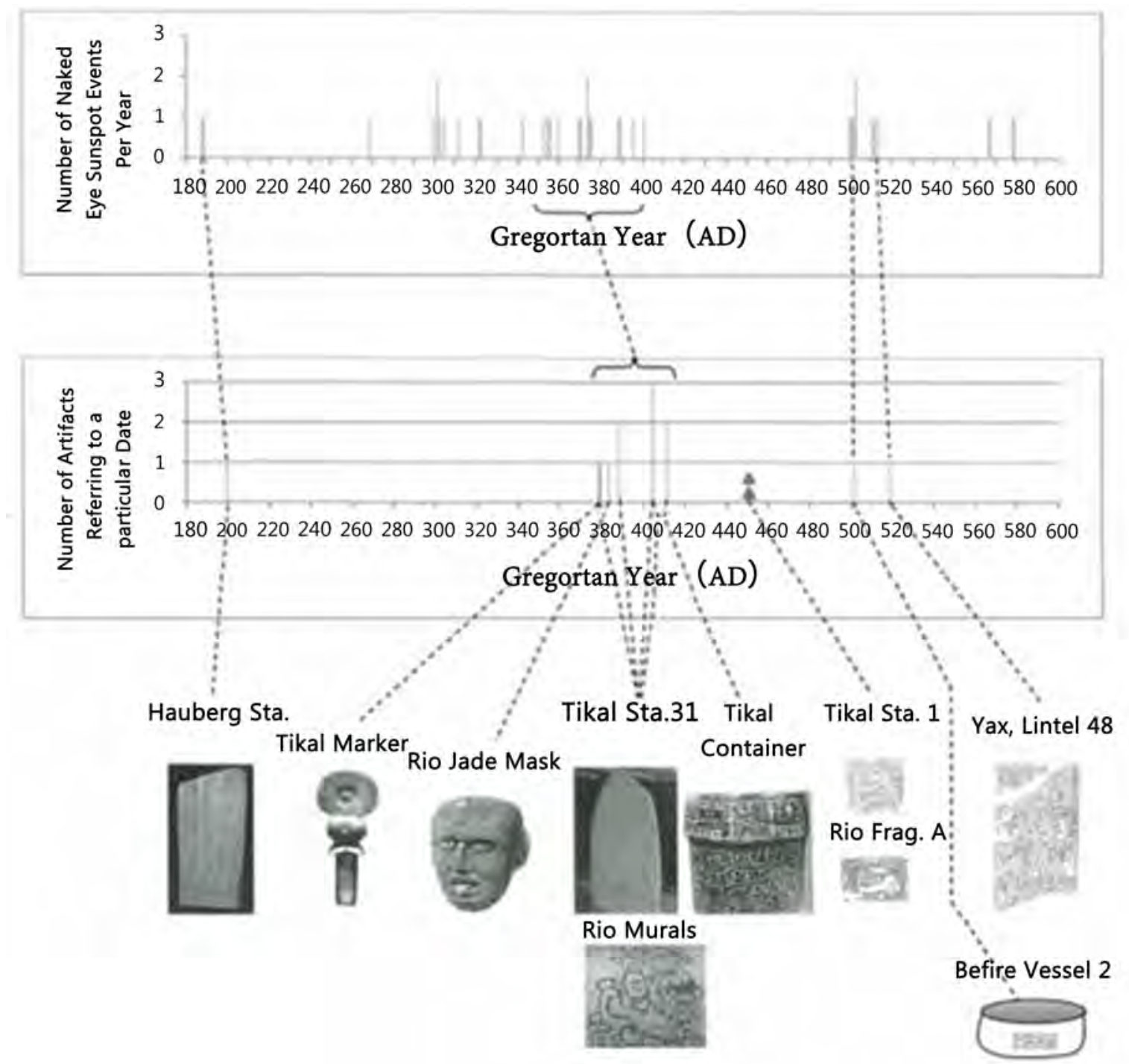

Figure 6. Summary of results for the current 10 artifacts of the Early Classic Period. At the top of this figure the number of Asian naked-eye sunspot observations versus time is plotted. Each bar (line) represents an observation, so that bars of double height represent two observations for a given year, etc. The middle of this figure shows the Mayan artifact count vs. time "spectrum". Eight of these artifacts show a spotted Sun God. The two small triangles mark the placement in time of artifacts with unspotted Sun God imagery; thereby verifying quiet Sun times. At the bottom are small representations of the 10 artifacts 
Each of the previous publications in this series has focused on one or more related artifacts. However, at this point, the total number of artifacts studied is great enough for a trend to begin to emerge (Figure 6). In general terms, there is agreement between solar active and quiet periods as recorded by Asian chroniclers and the appearance of solar deities in Mayan imagery (spotted or unspotted). Notice how the Mayan record is delayed in time relative to the Asian records. Because of the almost complete destruction of Mayan books, and in particular the great library at Merida, no one really knows if Mayan priest/astronomers recorded sunspots in their codices as soon as they were visible on the solar disk, as seems to be the case in Asia. Instead of books, scholars must rely on what has been recorded on stone monuments, pottery, and other physical objects. This is not a problem for pottery, which is easy to make, so that the time delay between a solar event and its recordation can be quite small (as little as 1 year; see Belize Vessel 2 in Figure 6). However, recording solar events in stone is more difficult and may require waiting for the sponsorship of some powerful noble who wishes to advertise his celestial connections on some important day (say, his accession to the throne). Therefore, greater time delays can be expected for stelas (as much as 13 years; see Yaxchilan Lintel 48 in Figure 6). The average time delay between an observed sunspot event and its appearance in Mayan art work is about 4.44 years. The time delay for most artifacts will be scattered about this mean with a standard deviation of about 3.8 years. Of the 10 artifacts discussed to date for the Early Classic Period, 8 are spotted and can be correlated with active Sun times (physical sunspot displays), while two are unspotted and fall within quiet Sun times. What is the probability that such a perfect correlation could occur by chance? During the Early Classic Period, the Sun was active $59 \%$ of the time, and quiet $41 \%$ of the time [19]. Therefore, the probability of achieving Figure 6 by chance is

$$
\begin{gathered}
\mathrm{P}(0 \text { errors })=(0.59)^{8}(0.41)^{2}=(0.0147)(0.168)=0.0025= \\
0.25 \% .
\end{gathered}
$$

A quarter of one percent is a small probability, and this figure will continue to drop precipitously over subsequent publications as the number of study artifacts greatly increases. Therefore, the probability is $99.75 \%$ that the perfect correlation in Figure 6 was not random, but intentional. That is to say, the artists who created these artifacts were aware of the condition of the Sun at the time referenced. Next, consider the probability of properly correlating 9 out of 10 artifacts by chance, but allowing one miscorrelation. If one of the spotted artifacts could not be correlated with a physical solar event and was orphaned in quiet Sun times, or if one of the unspotted artifacts correlated with some sunspot display, the probability would be,

$$
\begin{array}{r}
\mathrm{P}(1 \text { error })=8(0.59)^{7}(0.41)^{3}+2(0.59)^{9}(0.41)=0.01217+ \\
0.007104=0.01927=1.93 \%, \quad \text { (Eq. } 2)
\end{array}
$$

where the factor of 8 takes into account the fact that there are 8 ways for one of the 8 spotted artifacts to be marooned in quiet Sun times, and the factor of 2 takes into account the fact that there are 2 ways for one of the 2 unspotted artifacts to be associated with active Sun times. Notice that $\mathrm{P}(1$ error $)$ is a much larger probability than $\mathrm{P}(0$ errors $)$, as one might expect, but it is still small for only one error. The more errors that are allowed, the higher will be the probability until there is no correlation (what would be expected by random chance) between the spots on an artifact and the time period (active or quiet Sun times) from which they came.

\section{Acknowledgements}

The author would like to thank Tina Liu, formerly of the University of Arizona, for her help with the translation of Chinese references.

\section{REFERENCES}

[1] Zito RR. "Possible Mesoamerican Naked-eye Observation of Sunspots-V: Evidence from Río Azul Tomb I Murals and Related Artifacts”. Sociology and Anthropology. 2016 4(11): 953-965.

[2] Zito RR. "Possible Mesoamerican Naked-Eye Observation of Sunspots-I: Evidence from the Tikal Ball Court Marker”. In: Rappengluck MA, Rappengluck B, Campion N, Silva F, editors, Astronomy and Power: How Worlds Are Structured, Proceedings of the SEAC 2010 Conference. Oxford (UK): BAR 2794; 2016. p. 193-6.

[3] Zito RR. "Possible Mesoamerican Naked-Eye Observation of Sunspots - III: Evidence from the Hauberg Stela”. In: Šprajc I, Pehani P (editors). Ancient Cosmologies and Modern Prophets, Anthropological Notebooks, Year XIX Supplement. Ljubljana (Slovene): Slovene Anthropological Society; 2013. p. 339-46.

[4] Zito RR. "Possible Mesoamerican Naked-Eye Observation of Sunspots - IV: Evidence from Tikal Stela 31”. In: Šprajc I, Pehani P (editors). Ancient Cosmologies and Modern Prophets, Anthropological Notebooks, Year XIX Supplement. Ljubljana (Slovene): Slovene Anthropological Society; 2013. p. 347-55.

[5] Zito RR. "Possible Mesoamerican Naked-eye Observation of Sunspots-VI: Evidence from Yaxchilan Lintel 48”. Sociology and Anthropology 2017 5(12): 1041-1051.

[6] Zito RR. "Possible Mesoamerican Naked-Eye Observation of Sunspots-II: Evidence from the Codices". In: Rappengluck MA, Rappengluck B, Campion N, Silva F, editors, Astronomy and Power: How Worlds Are Structured, Proceedings of the SEAC 2010 Conference. Oxford (UK), BAR 2794; 2016. pp. 205-9.

[7] Thompson J. Eric S. A Catalogue of Maya Hieroglyphs: Norman (OK), U. of OK Press, 1962. pp. 153, 160, 221, 242-4, 291, 372. 
[8] Milbrath S. Star Gods of the Maya: Astronomy in Art, Folklore, and Calendars. Austin (TX), U. of Texas Press, 1999. pp. 101 (fig. a), 102, 136-7, 157-173, 206-7.

[9] Miller M, Taube K. An Illustrated Dictionary of The Gods and Symbols of Ancient Mexico and the Maya, London (UK), Tames \& Hudson, 1993. p. 59-60.

[10] Schlak A. Venus, Mercury, and the Sun: GI, GII, GIII of the Palenque Triad. Anthropology and Aesthetics. Vol. 29/30: pp. 181-202, 1996

[11] Villacorta CA. Villacorta JAC. The Dresden Codex. Walnut Creek (CA), Aegean Park Press, 1930. pp. 40-41.

[12] Zito RR. "A Comparison of Two Independent Models of the Solar System: Bode's Law and the 260 Day Mesoamerican Calendar”. In: Rubino-Martin J, Belmonte JA, Prada F, and Alberdi A, editors, Cosmology Across Cultures, Proceedings of the SEAC 2008 Conference. Granada (Spain): Astronomical Society of the Pacific Conference Series; Vol. 409, 2008, pp. 277-282.

[13] Adams REW and Mobley GF 1986, "Río Azul”. National Geographic. April 1986, pp. 420 -465.

[14]Anon. Trafficking Culture [Modified 2012 Aug. 14]. Available from http://trafficingculture.org/ encyc lopedia/cse-study/rio-azul-mask/, Accessed Dec. 13, 2013.

[15] Adams REW. Río Azul: An Ancient Maya City. Norman (OK), U. of OK Press, 1999. pp. 79, 216-7, 185.

[16] Hellmuth NM. Monsters und Menschen. Graz (Austria): Akademische Druck; 1987. pp. 70-1, 138, 140-1.

[17] Galindo-Trejo $\mathrm{J}$ and Allen C. Maya observations of $13^{\text {th }}$ century transits of Venus? In: Kurtz DW, editor. IAU Colloq. 196: Transits of Venus: New Views of the Solar System and Galaxy. Cambridge (UK), Cambridge U. press, 2005. pp. 124-37.

[18] Bray RJ, Loughhead RE. Sunspots. London (UK), Chapman and Hall, 1964. pp. 229.

[19] Clark D, Stephenson FR. An Interpretation of the
Pre-Telescopic Sunspot Records from the Orient. Q. J. R. Astr.Soc. Dec., 1978, 19: 387-410.

[20] McHargue J. A carving Sequence for Stela 1, Copan, Honduras. In: Macri MJ, McHargue (Editors). Eighth Palenque Round Table. San Francisco (CA), Pre-Columbian Art Research Institute, 1993. pp. 1-7.

[21] Fash WL, Fasquelle RA. History Carved in Stone: A Guide to the Archaeological Park of the Ruins of Copan. (Honduras), Instituto Hondureno De Antropologia E Historia, 1998. pp. 29.

[22] Stuart D. Stuart G. Palenque. London (UK), Thames \& Hudson, 2008. pp. 189-91, 246.

[23] Tedlock D. (Translator) Popol Vuh. New York (NY), Simon \& Schuster, 1985. p. 141

[24] Stone AJ. Images from the Underworld. Austin (TX), U. of TX Press, 1995. p. 163 (date for drawing 23),198-9.

[25] Faure G. Principles of Isotope Geology. New York (NY), John Wiley, 1977. pp. 323-49.

[26] Dansgaard W, Johnsen SJ, Møller J, Langway, Jr CC. One Thousand Centuries of Climate Record from Camp Century on the Greenland Ice Sheet. AAAS; Science, New Series, Vol. 166, No. 3903, Oct. 17, 1969, pp. 377-381.

[27] Anon. Tree Ring Data Bank. 2009. www.ncdc.noaa.gov/pal eo/treering.html.

[28] Kondrashov D, Feliks Y, Ghil M. Oscillatory modes of Nile River records (A.D. 622 - 1922). Geophy. Res. Let., Vol. 32, L10702, 2005, doi: 10.1029/2004GL022156.

[29] Ford WE. Dana's Textbook of Mineralogy, $4^{\text {th }}$ ed., John Wiley, NY., 1949, pp. 562-3, 574.

[30] Dud'a R. Rejl L. and Slivka D. Minerals of the World, Arch Cape Press, NY, 1986, pp.332, 152.

[31] Fritts HC. Tree Rings and Climate. Caldwell (NJ): Blackburn; 1976. p. 379. 